\title{
Estimation of Glycated Hemoglobin A(HbA1c) at Time of Pregnancy Diagnosis as A Discriminative Early Test for Women Vulnerable to Original Develop Gestational Diabetes Mellitus at the $24^{\text {th }}$ Gestational Week
} Article

\author{
Hatem Elgendy Abd Elsalam and Samar Ali Mohamed
}

Department of Obstetrics and Gynecology, Faculty of Medicine, Benha University, Egypt

\begin{abstract}
Aim: Estimation of blood glycated hemoglobin A (HbA1c) level in newly pregnant women at time of pregnancy diagnosis (T0) and 3-monthly thereafter to detect any relation between these levels and the change in maternal blood glucose (BG) levels during pregnancy.

Material and Methods: 304 newly pregnant women gave fasting blood samples for estimation of T0 HbA1c level and then underwent the 75-Oral glucose tolerance test (OGTT) and were asked to re-attend the clinic overnight fasting at the start of the $12^{\text {th }}$ and at the $24^{\text {th }}-28^{\text {th }}$ gestational week $(\mathrm{GW})$ for estimation of HbA1c levels and to repeat the 75-OGTT. $\triangle \mathrm{HbA} 1 \mathrm{c}$ was calculated as the difference between HbA1c levels estimated at $12^{\text {th }} \mathrm{GW}$ minus T0 levels. The results of the 75-OGTT were interpreted for diagnosis of gestational diabetes mellitus (GDM) and HbA1c at range of 4-6\% indicates non-diabetic state. Study outcome is the ability of T0 levels of HbA1c to discriminate women vulnerable to develop GDM around the $24^{\text {th }}$ to the $28^{\text {th }} \mathrm{GW}$.

Results: 38 women developed GDM, while 286 women completed their pregnancy free of GDM. GDM women had significantly higher T0 body mass index (BMI) and HbA1c levels than Non-GDM women. Moreover, the $12^{\text {th }}$ and $24^{\text {th }} \mathrm{GW}$ $\mathrm{HbA1c}$ levels and $\triangle \mathrm{HbAlc}$ were significantly higher in GDM women. The $24^{\text {th }} \mathrm{GW} 2 \mathrm{hr}$-postprandial BG (PPBG) levels showed significant positive correlation with T0 BMI, fasting BG and 2hr-PPBG and with T0 and 12th GW levels of HbA1c and $\triangle \mathrm{HbA} 1 \mathrm{c}$. Regression analysis defined T0 level of HbA1c, $\triangle \mathrm{HbA} 1 \mathrm{c}, 12^{\text {th }} \mathrm{GW} H \mathrm{HbA} 1 \mathrm{c}$ level and T0 BMI as the significant positive predictor for the $24^{\text {th }} \mathrm{GW} 2 \mathrm{hr}-\mathrm{PPBG}$ level. ROC curve analysis defined T0 level of HbA1c and $\Delta \mathrm{HbA} 1 \mathrm{c}$ as the significant predictors for the $24^{\text {th }} \mathrm{GW} 2 \mathrm{hr}-\mathrm{PPBG}$ level which is diagnostic for GDM.

Conclusion: Development and severity of GDM could be predicted at time of pregnancy diagnosis by high HbA1c level and assured by calculation of the extent of change in $\mathrm{HbA1c}$ level at the $12^{\text {th }} \mathrm{GW}$.
\end{abstract}

Key Words: Early predictors, gestational diabetes mellitus, glycated hemoglobin A

Received: 07 February 2021, Accepted: 30 March 2021

Corresponding Author: Hatem Elgendy Abd Elsalam, Department of Obstetrics and Gynecology, Faculty of Medicine, Benha University, Egypt, Tel.: 01090650463, E-mail: genedyhatem@gmail.com

ISSN: 2090-7265, May 2021, Vol.11, No. 2

\section{INTRODUCTION}

Glycation of biological macromolecules secondary to hyperglycemia leads to the formation of advanced glycation end products, a reaction which is accelerated in diabetes mellitus ${ }^{[1]}$. Glycated hemoglobin $(\mathrm{Hb} \mathrm{A} 1 \mathrm{c})$ is the conjugate acid of the Schiff base which develops through a nonenzymatic glycation reaction of human hemoglobin type $\mathrm{A}^{[2]}$. The reaction consists of initial non-covalent, reversible steps involving glucose and amino acid residues for the formation of labile $\mathrm{Hb} \mathrm{A} 1 \mathrm{c}^{[3]}$. Then, labile $\mathrm{Hb} \mathrm{A1c}$ undergo slow irreversible formation of stable $\mathrm{Hb} \mathrm{A1c}$ (the Amadori product), which is measured to assess diabetic $\operatorname{progression}^{[4]}$.

Glucose metabolism during pregnancy is governed by lactogenic hormones stimulating insulin production and counter-regulatory hormones inducing insulin resistance ${ }^{[5]}$ and disequilibrium between these two forces plays a major role in pathogenesis of metabolic disorders and carbohydrate metabolism ${ }^{[6]}$. Gestational diabetes mellitus (GDM) is defined as glucose tolerance disorder that starts during pregnancy and is associated with increased fetomaternal morbidity ${ }^{[7]}$. The International Association of Diabetes in Pregnancy documented that GDM carries a $41.5 \%$ and $10.7 \%$ risk of maternal prediabetes and type-2 diabetes, respectively after 11.4 years of follow up and is also associated with higher rates of childhood overweight and obesity ${ }^{[8]}$.

Pathogenesis of GDM was heavily studied but no definite underlying sole mechanism was determined ${ }^{[9]}$; disturbed levels of adipokines, which are substances of hormonal character that are secreted by adipose tissue were documented among women who later develop GDM than women completed their pregnancy free of $\mathrm{GDM}^{[10]}$. Insulin resistance increases during pregnancy which can lead to hyperinsulinemia, GDM, and neonatal hypoglycemia ${ }^{[11]}$. 
Screening of GDM at 24-28 gestational weeks (GW) delays its diagnosis and the implementation of prophylactic methods, thus necessitating improved screening strategies for early discrimination of vulnerable women ${ }^{[12]}$.

Moreover, international guidelines recommend early screening in the first trimester for overt diabetes and women who have a fasting blood glucose (FBG) levels diagnostic of GDM in later pregnancy are to be identified and treated despite uncertainty regarding the risks and benefits ${ }^{[13]}$.

\section{AIM OF THE WORK}

Estimation of blood $\mathrm{HbAlc}$ level in newly pregnant women at time of pregnancy diagnosis and 3-monthly thereafter to detect any relation between these levels and the change in maternal blood glucose levels during pregnancy.

\section{PATIENTS AND METHODS}

This is a prospective comparative clinical trial conducted at Department of Obstetrics and Gynecology, Benha University Hospitals and multiple private centers

The current study was conducted according to the conditions of the Local Ethical Committee since October 2018 till July 2020. All pregnant women who attended the Antenatal clinics for assurance of diagnosis of being pregnant and signed written fully informed consent to participate in the study were evaluated for eligibility for study inclusion. Demographic data of women assured to be pregnant were collected and included age, weight and height and baseline clinical and obstetric data. Body mass index (BMI) was calculated in $\mathrm{kg} / \mathrm{m}^{2}$ as weight $(\mathrm{kg}) /$ height $\left(\mathrm{m}^{2}\right)^{[14]}$.

Exclusion criteria include manifest DM, previous GDM in multipara women, morbid obesity with BMI $>35 \mathrm{~kg} / \mathrm{m}^{2[15]}$ and liver, or renal diseases. All pregnant women gave blood samples for estimation of random blood glucose to assure absence of manifest DM.

All women were asked to attend the clinic overnight fasting on the next day to give their baseline (T0) blood samples for estimation of $\mathrm{HbAlc}$ level and then underwent the 75-Oral glucose tolerance test (OGTT) which consists of estimation of FBG and postprandial BG (PPBG) levels at one and two hours after taking a 75-gm oral glucose diet. All women were asked to re-attend the clinic overnight fasting during at the start of the $12^{\text {th }}$ and at the $24^{\text {th }}-28^{\text {th }}$ gestational week (GW) for estimation of HbAlc levels and to repeat the 75-OGTT. $\triangle \mathrm{HbA} 1 \mathrm{c}$ was calculated as the difference between $\mathrm{HbA} 1 \mathrm{c}$ levels estimated at $12^{\text {th }} \mathrm{GW}$ and T0 levels.

Investigations: Venous blood samples $(5 \mathrm{ml})$ were collected from the antecubital vein under complete aseptic conditions and were divided into two parts; the first part was put in a tube containing sodium fluoride ( $2 \mathrm{mg}$ sodium fluoride/ $\mathrm{ml}$ blood) to prevent glycolysis for estimation of blood glucose levels using glucose oxidase method ${ }^{[16]}$ While, the second part was collected in EDTA containing tube for HbAlc estimation using Latex Turbidimetry (LINEAR CHEMICALS S.L. Joaquim Costa, Montgat, Barcelona, Spain $)^{[17]}$.

Interpretation of Results : The results of the 75OGTT were interpreted for diagnosis of GDM according to the recommendations of the International association of diabetes and pregnancy study groups ${ }^{[18]}$ as follows: $\mathrm{FBG} \geq 92 \mathrm{mg} / \mathrm{dl}, 1-\mathrm{h} \mathrm{BG} \geq 180 \mathrm{mg} / \mathrm{dl}$ and $2-\mathrm{h} \mathrm{BG} \geq 153$ $\mathrm{mg} / \mathrm{dl}$. Estimated levels of $\mathrm{HbAlc}$ at range of $4-6 \%$ indicates non-diabetic state, $6-6.5 \%$ indicates goal of control, $6.5-8 \%$ indicates good diabetic control and $>8 \%$ indicates need for interference to achieve control ${ }^{[19]}$.

Study outcomes : The ability of HbAlc levels estimated at T0 to discriminate women vulnerable to develop GDM around the $24^{\text {th }}$ to the $28^{\text {th }} \mathrm{GW}$. The relation between demographic data and HbA1c and development of GDM.

\section{STATISTICAL ANALYSIS}

The obtained data were presented as mean, standard deviation, numbers, percentages, median and interquartile ranges. Results were analyzed using One-way ANOVA for analysis of variance between groups, paired t-test for analysis within each group, Chi-square test ( $\mathrm{X}^{2}$ test) for analysis of non-numeric data and Mann-Whitney test for median values. Sensitivity and specificity of studied parameters as predictors were evaluated using the receiver operating characteristic (ROC) curve analysis judged by the area under the curve (AUC) compared versus the null hypothesis that $\mathrm{AUC}=0.05$ and paired-sample $\mathrm{AUC}$ differences was determined versus the null hypothesis that $\mathrm{AUC}=0$. Regression analysis (Stepwise method) was used for stratification of studied parameters as specific predictors. Statistical analysis was conducted using the SPSS (Version 15, 2006) for Windows statistical package. $P$ value $<0.05$ was considered statistically significant.

\section{RESULTS}

The study included 327 women eligible for evaluation, 23 women were excluded and 304 women were included in the study (Figure 1). Repeated OGTT at the $24^{\text {th }}$ to $28^{\text {th }} \mathrm{GW}$, diagnosed 38 women as having GDM (GDM group) for a frequency of GDM of $12.5 \%$, while the results of OGTT of the remaining 286 women $(87.5 \%)$ were within normal ranges and were considered as free of GDM (Non-GDM group). Women who developed GDM had significantly higher BMI at time of pregnancy diagnosis, while other demographic and clinical data of studied women showed non-significant differences between these women as being categorized as GDM and Non-GDM groups (Table 1)

Mean FBG and PPBG levels estimated at time of pregnancy diagnosis (T0) were non-significantly $(p>0.05)$ higher in GDM women compared to non-GDM women. At the $24^{\text {th }} \mathrm{GW}$, FBG and 2-hr PPBG levels were significantly 
higher in all women in comparison to their respective T0 levels and were significantly higher in GDM women compared to corresponding measures of non-GDM women at $24^{\text {th }} \mathrm{GW}$.

Concerning estimated levels of $\mathrm{HbA1c}$ at T0 samples mean estimated levels in women who later on developed GDM were significantly higher in comparison to levels estimated in women who continued their pregnancy free of GDM. Similarly, HbA1c levels estimated at $12^{\text {th }}$ and $24^{\text {th }} \mathrm{GW}$ were significantly higher in GDM women than in Non-GDM women. Moreover, $\triangle \mathrm{HbAlc}$ was significantly higher in GDM women than in Non-GDM women at $12^{\text {th }} \mathrm{GW}$ (Table 2, Figure 1).

Severity of DGM as judged by 2-hr PPBG levels estimated at $24^{\text {th }} \mathrm{GW}$ showed significant positive correlation with BMI ( $\mathrm{r}=0.165, p=0.003)$, FBG $(\mathrm{r}=0.128, p=0.022)$ and $2 \mathrm{hr}-\mathrm{PPBG}(\mathrm{r}=0.161, p=0.004)$ determined at time of pregnancy diagnosis and showed positive significant correlation with $\mathrm{T} 0$ and $12^{\text {th }} \mathrm{GW}$ levels of $\mathrm{HbA1c}$ and with $\Delta \mathrm{HbA1c}(\mathrm{r}=0.266,0.511$ and $0.379 ; p<0.001)$

Regression analysis (Stepwise method) defined HbA1c level estimated at time of pregnancy diagnosis (T0) as the persistently significant positive predictor for $2 \mathrm{hr}-\mathrm{PPBG}$ level estimated at the $24^{\text {th }} \mathrm{GW}$, followed by $\triangle \mathrm{HbA} 1 \mathrm{c}$, HbAlc level estimated at the $12^{\text {th }} \mathrm{GW}$ and the T0 BMI, while excluded the other variables as predictors for development or severity of GDM at the $24^{\text {th }} \mathrm{GW}$ (Table 3 ).

ROC curve analysis defined T0 level of HbAlc and $\triangle \mathrm{HbAlc}$ as the significant predictors for the $2 \mathrm{hr}-\mathrm{PPBG}$ estimated at the $24^{\text {th }} \mathrm{GW}$ which is diagnostic for GDM. However, paired-sample area difference under the ROC curves for T0 level of $\mathrm{HbA} 1 \mathrm{c}$ and $\triangle \mathrm{HbA} 1 \mathrm{c}$ showed non-significant difference (AUC difference $=-0.030 \pm 0.362$; $p=0.656$ ) in favor of T0 level of HbAlc (Table 4, Figure 2).
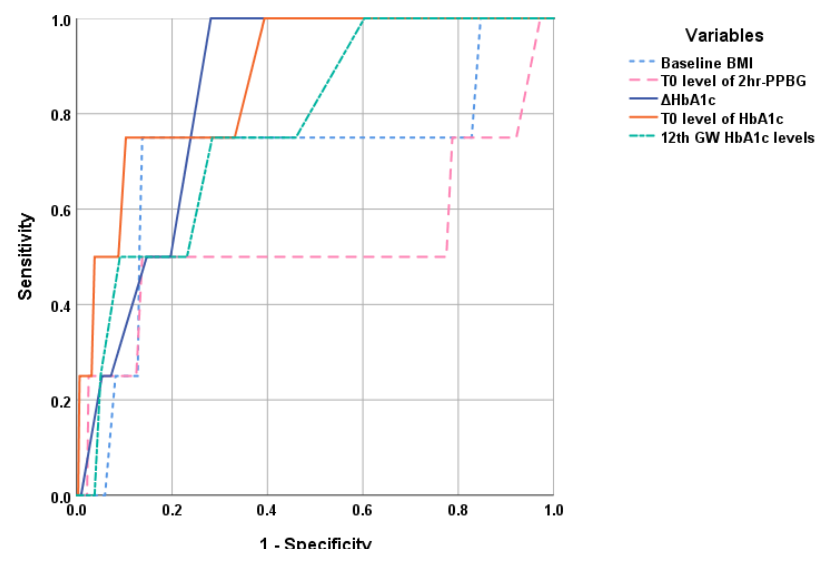

Fig. 1: ROC Curve analysis for predictors of $2 \mathrm{hr}-\mathrm{PPBG}$ level at the $24^{\text {th }} \mathrm{GW}$

Table 1: Demographic and clinical data determined at time of pregnancy diagnosis

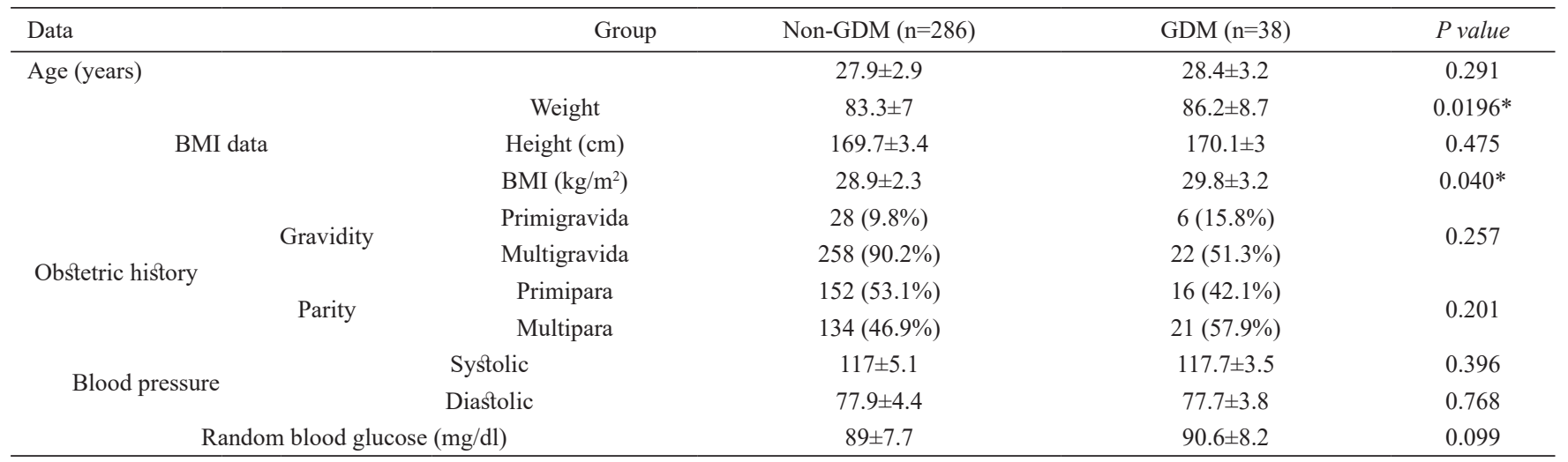

Data are presented as mean, standard deviation, numbers \& percentages; BMI: Body mass index; *: indicates significant difference 
Table 2: Results of 75-OGTT and estimation of HbA1c during pregnancy in women of both groups

\begin{tabular}{|c|c|c|c|c|c|c|c|}
\hline \multirow[b]{2}{*}{ Variable } & \multirow{2}{*}{$\begin{array}{l}\text { Time } \\
\text { Group }\end{array}$} & \multicolumn{3}{|c|}{ At T0 time } & \multicolumn{3}{|c|}{ At $24^{\text {th }}-28^{\text {th }} \mathrm{GW}$} \\
\hline & & Non-GDM $(n=286$ & & GDM $(n=38)$ & Non-GDM $(\mathrm{n}=286)$ & & GDM $(n=38)$ \\
\hline \multirow{8}{*}{ 75-OGTT } & FBG & $80.3 \pm 7$ & & $81.5 \pm 4.6$ & $81.7 \pm 8$ & & $101.4 \pm 8.5$ \\
\hline & 1-hr PPBG & $154.5 \pm 9.4$ & & $156.6 \pm 12.3$ & $157.1 \pm 10$ & & $194.4 \pm 32.9$ \\
\hline & 2-hr PPBG & $124.3 \pm 9.5$ & & $127.4 \pm 9.3$ & $126.1 \pm 10.6$ & & $163.5 \pm 8.6$ \\
\hline & \multirow{3}{*}{ P1 } & & & 0.313 & & & $<0.0001$ \\
\hline & & & & 0.217 & & & $<0.0001$ \\
\hline & & & & 0.061 & & & $<0.0001$ \\
\hline & \multirow{2}{*}{ P2 } & & & & 0.03 & & $<0.0001$ \\
\hline & & & & & 0.022 & & $<0.0001$ \\
\hline \multirow{6}{*}{$\mathrm{HbAlc}$} & Time & \multicolumn{2}{|l|}{ At T0 } & \multicolumn{2}{|c|}{ At $12^{\text {th }} \mathrm{GW}$} & \multicolumn{2}{|c|}{ At $24^{\text {th }}-28^{\text {th }} \mathrm{GW}$} \\
\hline & Group & Non-GDM (n=286) & GDM (n=38) & $\begin{array}{c}\text { Non-GDM } \\
(\mathrm{n}=286)\end{array}$ & GDM $(n=38)$ & $\begin{array}{c}\text { Non-GDM } \\
(\mathrm{n}=286)\end{array}$ & $\operatorname{GDM}(n=38)$ \\
\hline & Level & $4.3 \pm 0.4$ & $4.5 \pm 0.4$ & $4.5 \pm 0.3$ & $5.2 \pm 0.5$ & $5.2 \pm 0.7$ & $7.6 \pm 0.75$ \\
\hline & $\mathrm{P} 1$ & & 0.012 & & $<0.0001$ & & $<0.0001$ \\
\hline & $\Delta \mathrm{HbA} 1 \mathrm{c}$ & & & 0.1 (IQR: 0-0.3) & 0.65 (IQR: 0.4-0.9) & & \\
\hline & $\mathrm{P} 1$ & & & & $<0.0001$ & & \\
\hline
\end{tabular}

Data are presented as mean, standard deviation, percentages; GW: Gestational week; T0: Time of pregnancy diagnosis; GDM: Gestational diabetes mellitus; OGTT: Oral glucose tolerance test; HbA1c: Glycated hemoglobin A; $\Delta \mathrm{HbA} 1 \mathrm{c}=\mathrm{HbA} 1 \mathrm{c}$ level at $12^{\text {th }} \mathrm{GW}$ minus T0 level; P1 indicates significance of difference between GDM and Non-GDM groups; P2 indicates significance of difference between FAV and at 24-28 ${ }^{\text {th }} \mathrm{GW}$ findings; $P<0.05$ indicates significant difference; $P>0.05$ indicates non-significant difference

Table 3: Standardized Coefficient of included variable for Regression analysis for prediction of the $24^{\text {th }} \mathrm{GW} 2 \mathrm{hr}-\mathrm{PPBG}$ level as a measure for severity of GDM diagnosed at the $24^{\text {th }} \mathrm{GW}$

\begin{tabular}{lccccccc}
\hline \multirow{2}{*}{ Variables } & \multicolumn{2}{c}{ Model 1 } & \multicolumn{2}{c}{ Model 2 } & \multicolumn{2}{c}{ Model 3 } \\
\cline { 2 - 7 } & $\beta$ & $\mathrm{p}$ & $\beta$ & $\mathrm{p}$ & $\beta$ & $\mathrm{p}$ & $<$ \\
\hline T0 level of HbA1c & 0.415 & $<0.001$ & 0.431 & $<0.001$ & 0.511 & $<0.001$ & 0.511 \\
$\Delta$ HbA1c & 0.175 & $<0.001$ & 0.165 & $<0.001$ & 0.162 & 0.001 \\
12 $2^{\text {th }}$ GW HbA1c levels & 0.149 & 0.007 & 0.147 & 0.009 & & \\
Baseline BMI & 0.117 & 0.011 & & & & \\
\hline
\end{tabular}

B: Standardized Coefficient; T0: Time of pregnancy diagnosis; HbA1c: Glycated hemoglobin A; $\Delta \mathrm{HbA1c}=\mathrm{HbA1c}$ level at $12^{\text {th }}$ GW minus T0 level; BMI: Body mass index; $P$ indicates significance of the $\beta$ value; $P<0.05$ indicates significant difference; $P>0.05$ indicates non-significant difference

Table 4: Standardized Coefficient of included variable for Regression analysis for prediction of the $24^{\text {th }}$ GW $2 \mathrm{hr}$-PPBG level as a measure for severity of GDM diagnosed at the $24^{\text {th }} \mathrm{GW}$

\begin{tabular}{lcccc}
\hline Variables & AUC & Standard error & P value & $95 \%$ confidence interval \\
\hline Baseline BMI & 0.707 & 0.158 & 0.155 & $0.395-0.999$ \\
T0 level of HbA1c & 0.876 & 0.072 & 0.010 & $0.735-0.999$ \\
T0 level of 2hr-PPBG & 0.529 & 0.200 & 0.840 & $0.137-0.922$ \\
$12^{\text {th }}$ GW HbA1c levels & 0.774 & 0.099 & 0.059 & $0.579-0.969$ \\
$\Delta$ HbAlc & 0.845 & 0.049 & 0.018 & $0.750-0.941$ \\
\hline
\end{tabular}

AUC: Area under curve; T0: Time of pregnancy diagnosis; HbA1c: Glycated hemoglobin A; $\Delta \mathrm{HbA1c}=\mathrm{HbA1c}$ level at $12^{\text {th }}$ GW minus T0 level; BMI: Body mass index; GW: Gestational week; P indicates significance of the AUC; $P<0.05$ indicates significant difference; $P>0.05$ indicates non-significant difference

\section{DISCUSSION}

Estimated levels of $\mathrm{HbAlc}$ showed progressive increase with each estimation in comparison to that estimated at time of pregnancy diagnosis (T0). Moreover, T0 levels of HbAlc were significantly higher in GDM women in comparison to Non-GDM women. Similarly, multiple studies detected significantly higher HbAlc levels in women who developed GDM in comparison to those who completed their pregnancy free of GDM manifestations ${ }^{[20,21,22]}$.

Statistical analyses defined high T0 levels of HbAlc and high $\triangle \mathrm{HbAlc}$ as early specific discriminators for women vulnerable to development of GDM at the 24$26^{\text {th }} \mathrm{GW}$ and paired-sample area analysis for AUC for T0 level of HbA1c and $\triangle \mathrm{HbA} 1 \mathrm{c}$ showed non-significant difference in favor of T0 level of HbAlc, so that T0 
level of HbA1c could be considered as the significant early predictor for upcoming GDM, which spares time till the $12^{\text {th }} \mathrm{GW}$ before institution of prophylactic and/or therapeutic measures. In line with the results of statistical analyses, Zhuang et al., ${ }^{[23]}$ using multivariate logistic regression analysis showed that high BMI, 2-h PPBG and $\mathrm{HbAlc}$ were significant independent risk factors for GDM. Moreover, the results of a meta-analysis on the screening and diagnostic accuracy of $\mathrm{HbA} 1 \mathrm{c}$ test in pregnant women documented that the HbA1c test is simple, quick and more acceptable than the OGTT and can be considered as a specific test at a cut-off of $5.7 \%$ with $10 \%$ false positive rate ${ }^{[24]}$. Also, Immanuel et al., ${ }^{[25]}$ found $\mathrm{HbAlc}$ levels estimated during pregnancy significantly increase across the late GDM, early GDM, overt diabetes and T2DM groups, so can differentiate pregnant women according to pregnancy-imposed glucogenic effect and also found an early $\mathrm{HbA} 1 \mathrm{c} \geq 5.7 \%$ showed specificity for GDM diagnosis of $89.1 \%, 88.6 \%$ and $89.4 \%$, before $20^{\text {th }} \mathrm{GW}$, at $24-28^{\text {th }}$ GW and throughout gestation, respectively ${ }^{[26]}$.

ROC curve analysis defined FAV levels and $\triangle \mathrm{HbA} 1 \mathrm{c}$ are the significant predictors for upcoming GDM, but paired-test analysis for AUC favored FAV levels of HbA1c as a predictor. These findings go in hand with Lia et al., ${ }^{[27]}$ who found AUC of $\mathrm{HbAlc}$ level for detecting GDM was 0.664 and was significant versus the null hypothesis, and $\mathrm{HbA} 1 \mathrm{c}$ at $<5 \%$ has negative predictive value of $87.9 \%$ for possibility of getting diabetic. Also, Battarbee et al., ${ }^{[22]}$. evaluated HbAlc as a diagnostic test for early GDM compared with OGTT and found the AUC for HbA1c compared with OGTT was 0.80 and the optimal HbAlc threshold was $5.6 \%$ as it gives $64 \%$ sensitivity, $84 \%$ specificity for diagnosis of GDM.

The current study reported that all pregnant women showed a deviation towards hyperglycemia during pregnancy as noticed in women of Non-GDM group whose FBG and 2-hr PPBG levels estimated during 75-OGTT at the $24^{\text {th }} \mathrm{GW}$ were significantly higher in comparison to levels estimated during $\mathrm{T} 0$ tolerance test. Moreover, this hyperglycemia was exaggerated in some women who developed BG levels on 24-GW tolerance test diagnostic of GDM by a frequency of $12.5 \%$.

These findings point to a fact that pregnancy is a diabetogenic state, but certain women were vulnerable to manifest diabetic $\mathrm{BG}$ levels and go in hand with $\mathrm{Li}$ et al. ${ }^{[28]}$ who found the levels of FBG, PPBGG and insulin resistance scorings were significantly higher in GDM than in normal glucose tolerance women who showed progressive increase of their FBG and PPBG but do not approach the diagnostic level of GDM. Explanation of pathogenesis of gestational glucose intolerance is extremely important, but was still indefinite ${ }^{[29]}$ and Li et $a l .,{ }^{[28]}$ attributed it to progressively declining pancreatic $\beta$-cell function as manifested by increased insulin resistance scorings. As another explanation, disturbed levels of adipokines, which are secreted by adipose tissue, during pregnancy may play an important role in pathogenesis of gestational hyperglycemia, insulin resistance and progression to GDM. In support of such explanation, Francis et al., ${ }^{[10]}$. studied panel of adipokines; fatty acid binding protein-4, chemerin, and soluble leptin receptor and indicated a role for these adipokines in the pathogenesis of GDM with significant associations detected early in pregnancy before typical GDM screening time. Also, Gęca et al. ${ }^{[29]}$ found serum concentrations of $\mathrm{C} 1 \mathrm{q} /$ tumor necrosis factor-related protein-3, one of adipokines, were significantly higher in women with GDM, irrespective of being diet-or insulin treated or not treated at all in comparison to levels estimated in control group.

Interestingly, at time of diagnosis of pregnancy, women who developed GDM were found to have significantly higher BMI than non-GDM women and statistical correlations detected a positive significant correlation between BMI at time of pregnancy diagnosis and severity of GDM as judged by 2-hr PPBG during glucose tolerance testing at $24^{\text {th }} \mathrm{GW}$. In line with these findings, multiple previous studies found women with GDM had higher BMI than women free of $\mathrm{GDM}^{[30,31,32]}$ detected reduced risk of GDM with their proposed diet and exercise interventions for pregnant women versus women received no intervention. Recently, Qiu et al., ${ }^{[33]}$ reported that for pre-pregnancy BMI, significant differences were found in GDM incidence between the different groups according to BMI and Wang et al., ${ }^{[34]}$ found women with GDM with a predominant insulin-sensitivity defect had a higher preBMI. These findings could be attributed to the fact that plasma concentrations of adipokines, which may contribute directly and/or indirectly for glucose intolerance, are influenced by the amount of adipose tissue present before and/or during the pregnancy ${ }^{[35]}$.

\section{CONCLUSION}

Pregnancy induces maternal hyperglycemic state that may progress to GDM and was related to maternal BMI defined at time of diagnosis of pregnancy. Development and severity of GDM could be predicted at time of pregnancy diagnosis by high $\mathrm{HbA} 1 \mathrm{c}$ level and assured by calculation of the extent of change in $\mathrm{HbA} 1 \mathrm{c}$ level at the $12^{\text {th }} \mathrm{GW}$.

\section{CONFLICT OF INTERESTS}

There are no conflict of interests.

\section{REFERENCES}

1. Siddiqui Z, Faisal M, Alatar A, Ahmad S: Prevalence of auto-antibodies against D-ribose-glycatedhemoglobin in diabetes mellitus. Glycobiology. 2019 May 1; 29(5):409-418. Doi: 10.1093/glycob/cwz012.

2. Smith B, Mottishaw C, Hendricks A, Mitchell J, Becker S, Ropski P, et al: Potential roles of inorganic 
phosphate on the progression of initially bound glucopyranose toward the nonenzymatic glycation of human hemoglobin: mechanistic diversity and impacts on site selectivity. Cogent Biol. 2018; 4:1425196. Doi: 10.1080/23312025.2018.1425196.

3. Kazemi F, Divsalar A, Saboury A: Structural analysis of the interaction between free, glycated and fructated hemoglobin with propolis nanoparticles: A spectroscopic study. Int J Biol Macromol. 2018 Apr 1; 109:1329-1337. Doi: 10.1016/j.ijbiomac.2017.11.143.

4. Mottishaw C, Becker S, Smith B, Titus G, Holman $\mathrm{R}$, Rodnick $\mathrm{K}$ : Insights into the Progression of Labile $\mathrm{Hb}$ A 1c to Stable Hb A 1c via a Mechanistic Assessment of 2, 3-Bisphosphoglycerate Facilitation of the Slow Nonenzymatic Glycation Process. Hemoglobin. 2019 Jan; 43(1):42-49. Doi: 10.1080/03630269.2019.1597731.

5. Vejrazkova D, Vcelak J, Vankova M, Lukasova P, Bradnova O, Halkova T, et al: Steroids and insulin resistance in pregnancy. J Steroid Biochem Mol Biol. 2014; 139:122-9.

6. Vejrazkova D, Vankova M, Lukasova P, Vcelak J, Cirmanova V, Haluzik M, et al. Specific metabolic characteristics of women with former gestational diabetes: the importance of adipose tissue. Physiol Res. 2017; 66(Suppl. 3): S349-S356.

7. Kautzky-Willer A, Harreiter J, Winhofer-Stöckl Y, Bancher-Todesca D, Berger A, Repa A, Lechleitner M, Weitgasser R: [Gestational diabetes mellitus (Update 2019)] Wien Klin Wochenschr. 2019 May; 131(Suppl 1):91-102. Doi: 10.1007/s00508-018-1419-8.

8. Hod M, Kapur A, McIntyre H, FIGO Working Group on Hyperglycemia in Pregnancy; FIGO Pregnancy and Prevention of early NCD Committee: Evidence in support of the International Association of Diabetes in Pregnancy study groups' criteria for diagnosing gestational diabetes mellitus worldwide in 2019. Am J Obstet Gynecol. 2019 Aug; 221(2):109-116. Doi: 10.1016/j.ajog.2019.01.206.

9. Coetzee A, Sadhai N, Mason D, Hall D, Conradie M: Evidence to support the classification of hyperglycemia first detected in pregnancy to predict diabetes 6-12 weeks postpartum: A single center cohort study. Diabetes Res Clin Pract. 2020 Sep 10;169:108421. Doi: 10.1016/j.diabres.2020.108421.

10. Francis EC, Li M, Hinkle SN, Cao Y, Chen J, Wu $\mathrm{J}$, et al: Adipokines in early and mid-pregnancy and subsequent risk of gestational diabetes: a longitudinal study in a multiracial cohort. BMJ Open Diabetes Res Care. 2020 Jul; 8(1):e001333. Doi: 10.1136/ bmjdrc-2020-001333.

11. Eid J, Kechichian, Benavides E, Thibodeaux L, Salazar A, Saade G, Saad A: The Quantose Insulin Resistance Test for Maternal Insulin Resistance: A Pilot Study. Am J Perinatol. 2020 Sep 7. Doi: 10.1055/ s-0040-1716730.

12. Tai $\mathrm{Y}$, Lee $\mathrm{C}$, Kuo $\mathrm{C}$, Lin $\mathrm{M}$, Chen $\mathrm{K}$, Lin $\mathrm{S}$, et al: Simplifying the screening of gestational diabetes by maternal age plus fasting plasma glucose at first prenatal visit: A prospective cohort study. PLoS One. 2020 Aug 20; 15(8):e0237224. Doi: 10.1371/journal. pone. 0237224 .

13. Kuehn K, Gebuehr A, Wintour J, Woods A, Luu A, Wynne K:Significance of hyperglycemia in first trimester pregnancy (SHIFT): A pilot study and literature review. Aust N Z J Obstet Gynaecol. 2020 Sep 16. Doi: 10.1111/ajo.13254.

14. Bray GA: Pathophysiology of obesity. Am J Clin Nutr, 1992; 55: 488S-94S.

15. WHO: Physical status the use and interpretation of anthropometry. Report of a WHO Expert Committee. WHO Technical Report Series 854. Geneva: World Health Organization, 1995.

16. Tinder P: Determination of blood glucose. Ann. Clin. Biochem; 6:24, 1969.

17. Tietz NW: Textbook of Clinical Chemistry, Philadelphia WB. Saunders Company 1999: 794-795.

18. International association of diabetes and pregnancy study groups (IADPSG) recommendations on the diagnosis and classification of hyperglycemia in pregnancy. Diabetes Care. 2010; 33:676-682.

19. Charuruks N, Milintagas A, Watanaboonyoungcharoen $\mathrm{P}$,Ariyaboonsiri C: Determination of reference intervals of $\mathrm{HbA} 1 \mathrm{C}$ (DCCT/NGSP) and HbA1C (IFCC) in adults. J Med Assoc Thai., 2005 Jun;88(6):810-6

20. Sohn J, Lim H, Kim S, Kim T, Kim B, Hwang K, et al: Delayed diagnosis of gestational diabetes mellitus and perinatal outcomes in women with large for gestational age fetuses during the third trimester. Obstet Gynecol Sci. 2020 Sep; 63(5):615-622. Doi: 10.5468/ogs.20007. 
21. Deng L, Huang Y, Li L, Chen H, Su J: Serum miR$29 \mathrm{a} / \mathrm{b}$ expression in gestational diabetes mellitus and its influence on prognosis evaluation. J Int Med Res. 2020 Sep; 48(9):300060520954763.

22. Battarbee A, Grant J, Vladutiu C, Menard M, Clark M, Manuck T, et al: Hemoglobin A1c and Early Gestational Diabetes. J Womens Health (Larchmt). 2020 Jul 15. Doi: 10.1089/jwh.2019.8203.

23. Zhuang W, Lv J, Liang Q, Chen W, Zhang S, Sun $\mathrm{X}$ : Adverse effects of gestational diabetes-related risk factors on pregnancy outcomes and intervention measures. Exp Ther Med. 2020 Oct; 20(4):3361-3367. Doi: 10.3892/etm.2020.9050.

24. Amaefule C, Sasitharan A, Kalra P, Iliodromoti S, Huda M, Rogozinska E, et al: The accuracy of haemoglobin A1c as a screening and diagnostic test for gestational diabetes: a systematic review and metaanalysis of test accuracy studies. Curr Opin Obstet Gynecol. 2020 Oct; 32(5):322-334. Doi: 10.1097/ GCO.0000000000000648.

25. Immanuel J, Eagleton C, Baker J, Simmons D: Pregnancy outcomes among multi-ethnic women with different degrees of hyperglycemia during pregnancy in an urban New Zealand population and their association with postnatal HbAlc uptake. Aust N Z J Obstet Gynaecol. 2020 Sep 2. Doi: 10.1111/ajo.13231.

26. Immanuel J, Simmons D, Desoye G, Corcoy R, Adelantado J, Devlieger R, et al: Performance of early pregnancy $\mathrm{HbA} 1 \mathrm{c}$ for predicting gestational diabetes mellitus and adverse pregnancy outcomes in obese European women. Diabetes Res Clin Pract. 2020 Aug 21; 168:108378. Doi: 10.1016/j.diabres.2020.108378.

27. Lai Y, Hanxiao Chen, Ze Du, Shu Zhou, Wenming Xu, Tao Li: The diagnostic accuracy of HbAlc in detecting gestational diabetes mellitus among Chinese pregnant individuals. Ann Transl Med. 2020 Aug; 8(16):1014. Doi: 10.21037/atm-20-5464.

28. Li L, Lee SJ, Kook SY, Ahn TG, Lee JY, Hwang JY: Serum from pregnant women with gestational diabetes mellitus increases the expression of FABP4 mRNA in primary subcutaneous human pre-adipocytes. Obstet Gynecol Sci. 2017; 60(3):274-282

29. Gęca T, Kwiatek M, Krzyżanowski A, Kwaśniewska A:C1q/TNF-Related Protein-3 (CTRP-3) and Pigment Epithelium-Derived Factor (PEDF) Concentrations in Patients with Gestational Diabetes Mellitus: A CaseControl Study. J Clin Med. 2020 Aug 10;9(8):2587. Doi: $10.3390 / \mathrm{jcm} 9082587$.

30. Pan SC, Huang CC, Lin SJ, Chen BY, Chang CC, Leon Guo YL: Gestational diabetes mellitus was related to ambient air pollutant nitric oxide during early gestation. Environ Res. 2017; 158:318-323.

31. Lindsay KL, Brennan L, Kennelly MA, Curran S, Coffey M, Smith TP, Foley ME, Hatunic M, McAuliffe FM: Maternal metabolic response to dietary treatment for impaired glucose tolerance and gestational diabetes mellitus. Ir J Med Sci. 2018 Jan 20. Doi: 10.1007/ s11845-018-1744-y

32. Shepherd E, Gomersall JC, Tieu J, Han S, Crowther CA, Middleton P: Combined diet and exercise interventions for preventing gestational diabetes mellitus. Cochrane Database Syst Rev. 2017; 11:CD010443.

33. Qiu J, Liu Y, Zhu W, Zhang C: Comparison of Effectiveness of Routine Antenatal Care with a Midwife-Managed Clinic Service in Prevention of Gestational Diabetes Mellitus in Early Pregnancy at a Hospital in China. Med Sci Monit. 2020 Sep 27; 26:e925991.Doi: 10.12659/MSM.925991.

34. Wang N, Lin Song L, Sun B, Peng Y, Fei S, Cui J, et al. Contribution of gestational diabetes mellitus heterogeneity and prepregnancy body mass index to large-for-gestational-age infants-A retrospective case-control study. J Diabetes. 2020 Sep 15. Doi: 10.1111/1753-0407.13113.

35. de Gennaro G, Palla G, Battini L, Simoncini T, Del Prato S, Bertolotto A, Bianchi C: The role of adipokines in the pathogenesis of gestational diabetes mellitus. Gynecol Endocrinol. 2019 Sep; 35(9): 737-751. Doi: 10.1080/09513590.2019.1597346. 